\title{
Weight of preterm newborns during the first twelve weeks of life
}

\section{L.M. Anchieta ${ }^{1}$, \\ C.C. Xavier ${ }^{2}$, \\ E.A. Colosimo ${ }^{3}$ \\ and M.F. Souza ${ }^{4}$}

\author{
${ }^{1}$ Maternidade Odete Valadares, Fundação Hospitalar do Estado de Minas Gerais \\ and Hospital Universitário, Universidade Federal de Minas Gerais, \\ Belo Horizonte, MG, Brasil \\ ${ }^{2}$ Departamento de Pediatria, Universidade Federal de Minas Gerais, \\ Belo Horizonte, MG, Brasil \\ ${ }^{3}$ Departamento de Estatística, Instituto de Ciências Exatas, \\ Universidade Federal de Minas Gerais, Belo Horizonte, MG, Brasil \\ ${ }^{4}$ Maternidade Odete Valadares, Fundação Hospitalar do Estado de Minas Gerais, \\ Belo Horizonte, MG, Brasil
}

\section{Correspondence}

L.M. Anchieta

Rua Tupis, 426, Apto. 1104

30190-060 Belo Horizonte, MG

Brasil

E-mail: lenima@terra.com.br

$\ldots \ldots \ldots \ldots \ldots \ldots \ldots$

Received May 8, 2002

Accepted February 18, 2003

\begin{abstract}
A longitudinal and prospective study was carried out at two stateoperated maternity hospitals in Belo Horizonte during 1996 in order to assess the weight of preterm appropriate-for-gestational-age newborns during the first twelve weeks of life. Two hundred and sixty appropriate-for-gestational-age preterm infants with birth weight $<2500 \mathrm{~g}$ were evaluated weekly. The infants were divided into groups based on birth weight at 250 -g intervals. Using weight means, somatic growth curves were constructed and adjusted to Count's model. Absolute (g/day) and relative $\left(\mathrm{g} \mathrm{kg}^{-1}\right.$ day $\left.^{-1}\right)$ velocity curves were obtained from a derivative of this model. The growth curve was characterized by weight loss during the 1st week (4-6 days) ranging from 5.9 to $13.3 \%$ (the greater the percentage, the lower the birth weight), recovery of birth weight within 17 and 21 days, and increasingly higher rates of weight gain after the $3 r d$ week. These rates were proportional to birth weight when expressed as $\mathrm{g} /$ day (the lowest and the highest birth weight neonates gained 15.9 and $30.1 \mathrm{~g} /$ day, respectively). However, if expressed as $\mathrm{g} \mathrm{kg}^{-1} \mathrm{day}^{-1}$, the rates were inversely proportional to birth weight (during the 3rd week, the lowest and the highest weight newborns gained 18.0 and $11.5 \mathrm{~g} \mathrm{~kg}^{-1} \mathrm{day}^{-1}$, respectively). During the 12th week the rates were similar for all groups ( 7.5 to $10.2 \mathrm{~g} \mathrm{~kg}^{-1}$ day $\left.^{-1}\right)$. The relative velocity accurately reflects weight gain of preterm infants who are appropriate for gestational age and, in the present study, it was inversely proportional to birth weight, with a peak during the 3rd week of life, and a homogeneous behavior during the 12th week for all weight groups.
\end{abstract}

Key words

- Premature infants

- Growth curves

- Growth velocity 


\section{Introduction}

Preterm neonates are born before maturation of the physiological systems that are essential for extrauterine life. Their major problems result from the functional immaturity of these systems. One of the roles played by neonatologists and intensive care units is to support these immature systems through health care strategies designed to overcome some of the limitations. These developments in intensive care have led to a significant decrease in neonatal mortality rates, such as $4.6 \%$ in the United States (1) and $13.6 \%$ in Brazil (2). In the past 30 years, no other medical field has demonstrated such a marked decrease in mortality and morbidity, although the prematurity rate, ranging from 6 to $10 \%$ in the United States, has not shown significant changes in the past 40 years (3).

An essential aspect of neonatal care is growth assessment, since from intrauterine to extrauterine life the maternal nutrition source is interrupted and energy expenditure increases, making it difficult to achieve a positive energy balance sufficient to promote growth.

In addition, it is possible that the intrauterine growth rate under optimum conditions is not an adequate and probably not even an "ideal" parameter for predicting the growth of preterm newborns under adverse clinical conditions.

The study by Dancis et al. (4) is still a reference for the assessment of preterm infant growth in current neonatal care. Other studies (5-12) have used several methodologies to evaluate preterm infant growth. The assessment of weight gain dynamics during the first weeks of postnatal life in preterm newborns has provided valuable data $(10,13-$ 15).

The objective of the present study was to examine body weight as a growth indicator using a longitudinal and prospective approach to current neonatal care conditions, taking into account the methodological differences that hamper comparisons between studies, basically because of markedly diverse infant populations and neonatal care changes primarily due to developments in nutrition.

\section{Material and Methods}

The subjects of this study were appropriate-for-gestational-age preterm infants (16) with birth weight $<2500 \mathrm{~g}$, born at Odete Valadares Maternity (Hospital Foundation of the State of Minas Gerais) (MOV/ FHEMIG) and at the University Hospital (Federal University of Minas Gerais, HC/ UFMG), from January to December 1996, whose mothers or guardians consented to take part in the study. This investigation was approved by the Medical Ethics Committee of UFMG on May 31st, 1996.

Gestational age was preferentially estimated based on information given by the mothers about the date of their last menstrual period, accepted as correct and confirmed, whenever possible, by ultrasonography performed before 20 weeks of gestation. When mothers were not sure about the date and no ultrasonography was available, gestational age was confirmed by clinical and neurological examination (17), accepting a difference of as much as two weeks. In the absence of this information, clinical and neurological examinations were used.

Exclusion criteria were congenital infections and/or severe congenital malformations, multiple birth, severe neurological disorders, adverse clinical progression preventing measurements or interfering with parenteral and/or enteral nutrition, drug and substance abuse by the mother, enteral nutrition started after the first week of life, and death during the study.

Infants were divided into groups based on birth weight at 250 -g intervals, with the lower limit being $750 \mathrm{~g}$ (included) and the upper limit $2500 \mathrm{~g}$ (excluded). Weight was recorded at birth and on day 3 , and after day 7 it was measured weekly up to 84 days of 
life (12 weeks). The maximum tolerance accepted for these records regarding time was up to three hours of life at birth, \pm 1 day on days 3 and 7 , and \pm 2 days from day 14 to 84. Clinical progression and fluid and energy intake were monitored at the same intervals.

Birth weight was recorded in the neonatal care room by a trained professional (nurse or physician) using a standardized technique. The remaining measurements were made by the researchers in the morning, one hour before the first meal. During outpatient follow-up, weight was recorded in the afternoon, always at the same time. Children were weighed naked and scales were calibrated. If the infant was using an endotracheal tube for assisted ventilation and/or venipuncture material, the equipment weight was subtracted based on a previously established chart. Electronic pediatric scales were used (Filizola Baby scale, São Paulo, SP, Brazil; $15-\mathrm{kg}$ capacity and 5-g sensitivity) and were calibrated every 6 months.

The nutritional recommendations for preterm infants at both hospitals were based on routine nutritional care and were planned to provide a calorie intake of $120-130 \mathrm{cal} \mathrm{kg}^{-1}$ day $^{-1}$ and a fluid intake of $180-200 \mathrm{ml} \mathrm{kg}^{-1}$ day $^{-1}$ by the end of the 2 nd week of life. The infants were kept warm in incubators with or without a thermal tunnel and heat loss was estimated, with appropriate adjustments of fluid rates. Parenteral nutrition, when indicated, was introduced on the 3rd day of life and babies were weaned when enteral intake was approximately $80 \mathrm{cal} \mathrm{kg}^{-1} \mathrm{day}^{-1}$. The enteral diet was introduced as early as possible as minimal enteral nutrition, preferably with milk from the baby's mother. The standardized diets at the hospitals are raw or pasteurized human milk, formulas for term and preterm infants and semi-elemental formulas for special cases. During outpatient follow-up, breast-feeding was always the first choice, and relactation was attempted at the institutions for high-risk infants who were unable to breast-feed for a long period of time. If supplementation or use of artificial milk was necessary due to difficulty in breastfeeding, the mothers were instructed to use term infant formula whenever possible.

\section{Statistical model}

Growth may be defined as the process by which the individuals change in size and shape during a certain period of time. This phenomenon is studied by making sequential measurements in the same individual at regular intervals and using serial data to establish behavioral patterns. The longitudinal growth data analysis requires specific statistical methodologies that involve adjustment of nonlinear models to the parameters.

Adjusting growth curves to longitudinal data involves the description and summary of the growth process with a limited number of parameters. These parameters characterize the growth pattern and have the same meaning for all individuals, thus allowing comparisons between individuals and groups.

The main contribution of the statistical study was to obtain mathematical models representing the behavior of somatic growth and growth velocity data. The Epi Info software, version 6.0, was used for weight measurement analysis by calculating the mean and standard deviation.

The literature reports some mathematical models to explain the behavior of growth curves. Hauspie (18) published an excellent review of these models, and some models were selected from his study bearing in mind simplicity and constant use in problems such as the following:

1a. Second order polynomial: $y=b_{0}+b_{1}$ $*$ time $+b_{2} *$ time ${ }^{2}$

1b. Third order polynomial: $y=b_{0}+b_{1} *$ time $+\mathrm{b}_{2} *$ time $^{2}+\mathrm{b}_{3} *$ time $^{3}$

2. Logistic: $y=p+\frac{\text { alpha }}{1+\exp \left(\mathrm{b}_{0}+\mathrm{b}_{1} * \text { time }\right)}$ 
3. Monomolecular (Jenss-Baykey):

$$
\mathrm{y}=\text { alpha }+\mathrm{p} * \text { time }-\exp \left(\mathrm{b}_{0}+\mathrm{b}_{1} * \text { time }\right)
$$

4. Count: $y=$ alpha $+p *$ time $+b_{0}$

*LN(time +1$)$

The regression models cited above were adjusted by the least squares method using statistical software (SPSS). Observe that models 2 and 3 have nonlinear parameters and require special routines to be adjusted, whereas models $1 \mathrm{a}, 1 \mathrm{~b}$ and 4 have linear parameters and routines for their adjustment are available in all statistical softwares and Excel worksheets. Parameters were estimated considering all sampling values as well as only the means of each recording time.

All predicted curves closely followed the observed curves. However, only Count's curve demonstrated a decrease in the second reading time (3 days), as shown in Figure 1.

A numerical criterion extensively used to discriminate nonlinear regression models is the adjusted coefficient of determination $\left(\mathrm{R}_{\mathrm{A}}^{2}\right)(19)$ expressed as follows:

$$
\mathrm{R}_{\mathrm{A}}^{2}=1-\left(\frac{\mathrm{n}-1}{\mathrm{n}-\mathrm{p}}\right)\left(1-\mathrm{R}^{2}\right)
$$

where $n$ : sample size, $p$ : number of model parameters, $R^{2}$ : adjusted coefficient of determination by least squares.

Count's model showed the best behavior according to this criterion, and was chosen based on its strengths: it satisfactorily follows the behavior observed in growth curves, and it was the only model that decreased at the second recording time (3 days); it is easy to estimate because it has linear parameters; it has the best performance according to the numerical criterion (predicted value close to the observed value).

To assess weight gain velocity, a fundamental clinical aspect in monitoring and understanding preterm infant growth dynamics, two analyses were used in the present study: absolute velocity, i.e., daily weight gain, and relative velocity, or daily weight gain/kg weight.

Absolute velocity was calculated based on the mathematical equation derivative of the model, which explains the behavior of longitudinal weight data. Therefore, for Count's model we have:

$$
\text { growth rate }=p+\frac{b_{0}}{\text { time }+1}
$$

Using the estimated values, velocity curves were obtained for the seven categories.

\section{Results}

Of 270 infants included in the study 260 were followed-up (loss of 3.7\%); 179 (68.8\%) of the 260 neonates were born at MOV/ FHEMIG. The distribution of infants by sex showed a slight predominance of males, i.e., 137 (52.7\%).

A weight development curve was constructed for each of the seven birth weight categories the preterm infants were divided into. Table 1 shows the upper and lower limits and mean weight and gestational age at birth.

Weekly mean weight values were used to construct the curves for longitudinal analysis of weight development of preterm infants who were appropriate for gestational age showing weight and chronological age. Count's model was applied, as demonstrated in Figure 2. Growth dynamics is shown in a clear-cut manner and weight loss, stabilization and gain of all curves are graphically similar.

Figures 3 and 4 demonstrate the velocity curves for each weight category as of day 7 , since weight loss occurs during the first seven days of life, with consequent negative velocity rates. Figure 3 presents the mean weight gain velocities as $\mathrm{g} /$ day based on a Count's model derivative. Note that the seven curves are parallel, curves 5 and 7 overlap as of four weeks and are below curves 4 and 6 . Figure 3 also demonstrates that the largest infants 
(curve 6) gained virtually twice the weight as the small ones (curve 1) along the follow-up period (for instance, weight gain was 33.3 and $15.9 \mathrm{~g}$ /day for infants in curves 6 and 1 , respectively, during the $3 \mathrm{rd}$ week, and 41.4 and $22.1 \mathrm{~g} /$ day for the same curves during week 12).

Figure 4 presents mean weight gain velocity as $\mathrm{g} \mathrm{kg}^{-1}$ day $^{-1}$, showing a marked increase from the 1 st to the 4th week (up to the 3 rd week) in all seven curves. Nevertheless, curves 1 and 2 present gains of 17.9 and $18.1 \mathrm{~g} \mathrm{~kg}^{-1}$ day $^{-1}$, respectively, during the $3 \mathrm{rd}$ week, and curve 7 shows a gain of $11.5 \mathrm{~g}$ $\mathrm{kg}^{-1}$ day $^{-1}$. Later there was a drop, and at the end of the follow-up period, by week 12 , weight gain was $10.2 \mathrm{~g} \mathrm{~kg}^{-1}$ day $^{-1}$ in curve 1 , and $7.5 \mathrm{~g} \mathrm{~kg}^{-1}$ day $^{-1}$ in curve 7 . Note that curves 1 and 2 are overlapping, showing a closely similar weight gain in $\mathrm{g} \mathrm{kg}^{-1}$ day $^{-1}$ between the two infant categories.

Another way to evaluate growth dynamics is to consider the somatic growth and weight gain velocity $\left(\mathrm{g} \mathrm{kg}^{-1}\right.$ day $\left.^{-1}\right)$ curves when observed in relation to corrected age. As an example, Figure 5 shows the curves for the smallest newborns (curve 1) and for the largest newborns (curve 7). Adequatefor-gestational-age newborns for curve 1 presented a mean gestational age of 27 weeks at birth, and those for curve 7 presented a mean gestational age at birth of 35 weeks. The newborns of curve 1 had a higher weight gain velocity per $\mathrm{kg}$ compared to the larger newborns and that later the smaller newborns tended to approximate and reach the weight of the larger newborns.

Figure 6 illustrates the growth dynamics for all the birth weight categories of adequate-for-gestational-age preterm newborns, showing that weight gain velocity, when expressed as $\mathrm{g} \mathrm{kg}^{-1}$ day $^{-1}$, is inversely proportional to birth weight. There was a clear trend for lower birth weight infants to approximate and reach the weight of larger newborns, in agreement with literature data $(20-22)$.
With respect to nutritional support, it can be seen that the newborns of curve 1 only reached a mean calorie intake of $120 \mathrm{cal} \mathrm{kg}^{-1}$ day $^{-1}(23,24)$ starting at six weeks of life (42nd day), those of curve 2 did so after five weeks (35th day), those of curve 3 after three weeks (21st day), and those of curve 4 after two weeks (14th day). The newborns of curve 5 were already feeding on demand (understood here as ingestion of the enteral diet controlled by the wish and need of the newborn itself) during the second week of life, and those of curves 6 and 7 did so during the first week of life. In addition, the beginning of the enteral diet was more delayed the lower the birth weight, with a median of 5 days for the newborns of curves 1 and 2, of 3 days for those of curve 3 , of 2 days for those of curve 4 , and of 1 day for those of curves 5 , 6 and 7 . The median time of use of parenteral nutrition ranged from 5 to 14 days and its beginning ranged from 3 to 5 days of life for the various curves.

\section{Discussion}

Count's model demonstrated growth dynamics in a clear manner, indicating a period of weight loss during the 1st week of life (56 days) for all curves, a birth weight recovery period between the 2nd and 3rd week (17-24 days), followed by a weight gain period. Somatic growth dynamics was graphically similar for all infant categories (Figure 2). The weight development of appropriate-forgestational-age preterm infants in this study was similar to that described by most authors (5-12) for preterm infants with no intrauterine growth retardation with respect to the biphasic nature of the weight curve, time and duration of the initial weight loss and effect of birth weight on weight gain.

Little is known about the dynamics of postnatal preterm infant growth since few longitudinal studies evaluating growth velocity are available. No study on growth related to birth weight (5-11) as discussed in 


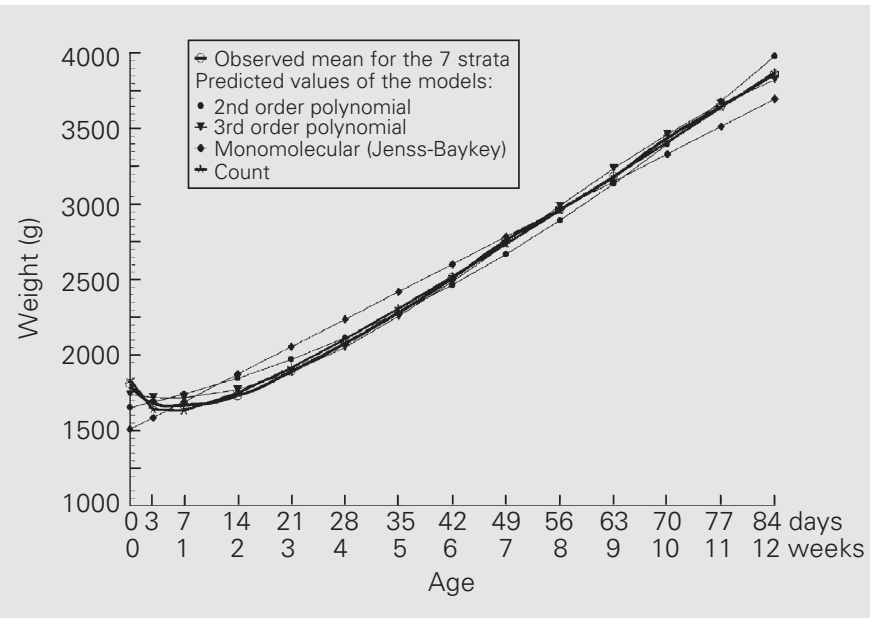

Figure 1. Comparison of the mathematical models evaluated in terms of the observed mean.

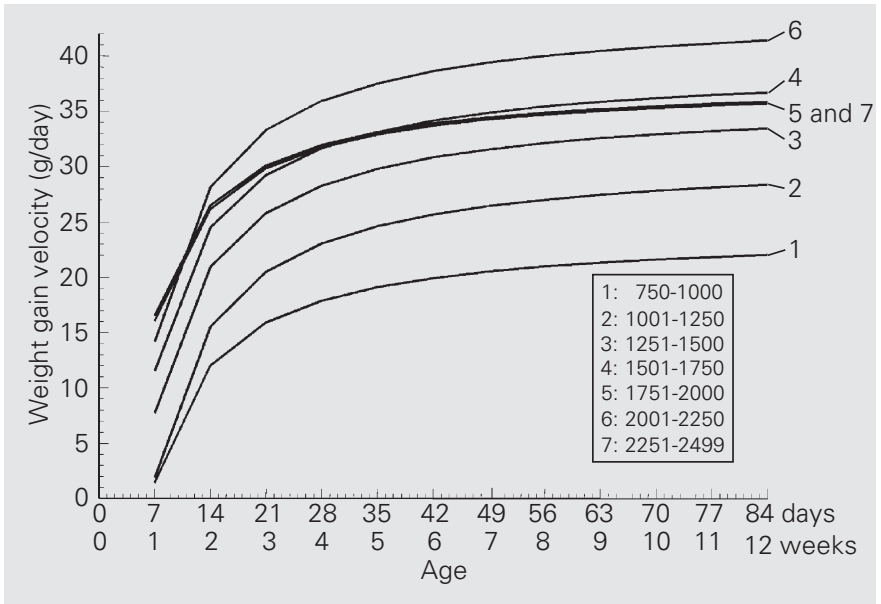

Figure 3. Mean daily weight gain velocity ( $g /$ day) of preterm newborns by birth weight category.

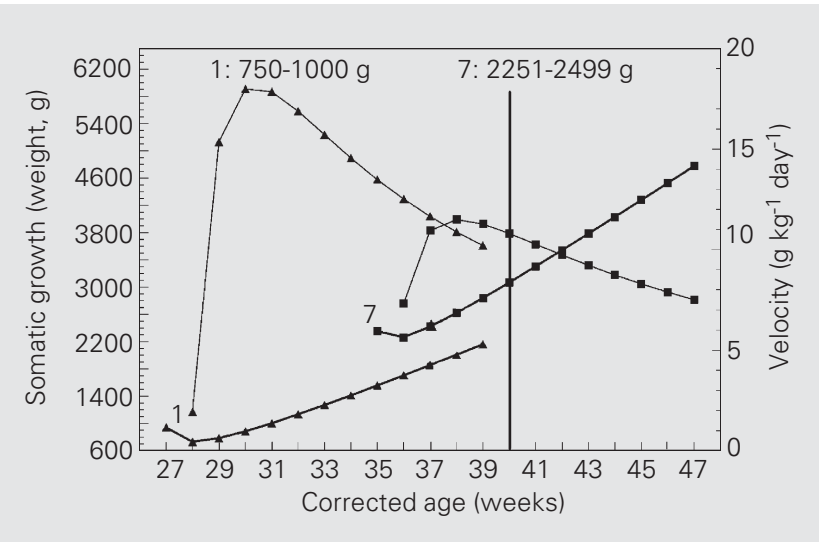

Figure 5. Growth dynamics of adequate-for-gestational-age preterm newborns (curves 1 and 7): somatic growth and velocity with respect to corrected age.

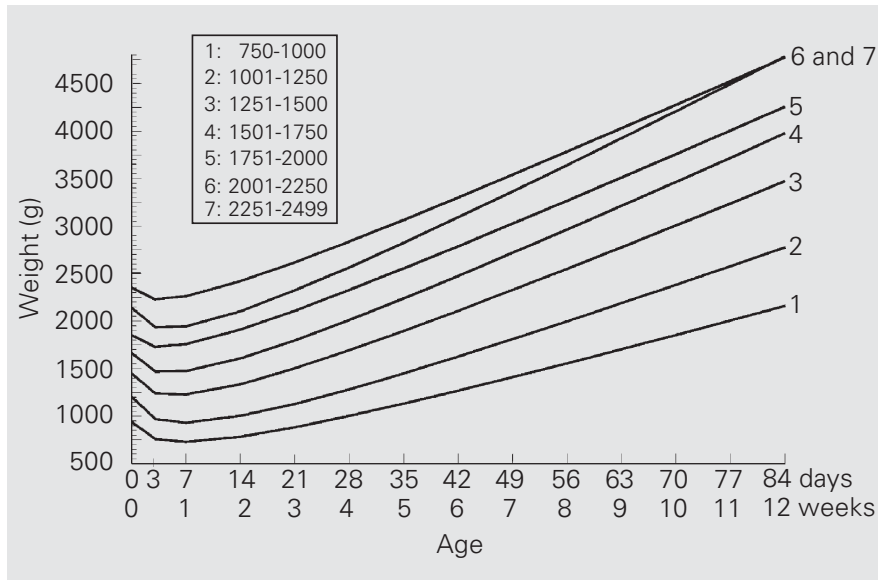

Figure 2. Mean weight of preterm newborns by birth weight category adjusted by the method of Count.

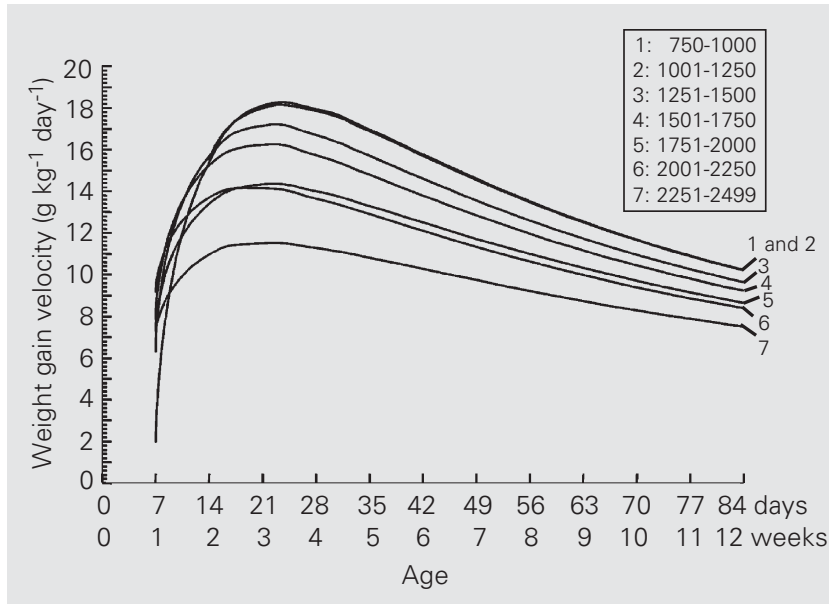

Figure 4. Mean daily weight gain velocity per $\mathrm{kg}\left(\mathrm{g} \mathrm{kg}^{-1} \mathrm{day}^{-1}\right)$ of adequate-for-gestational-age preterm newborns by birth weight category.

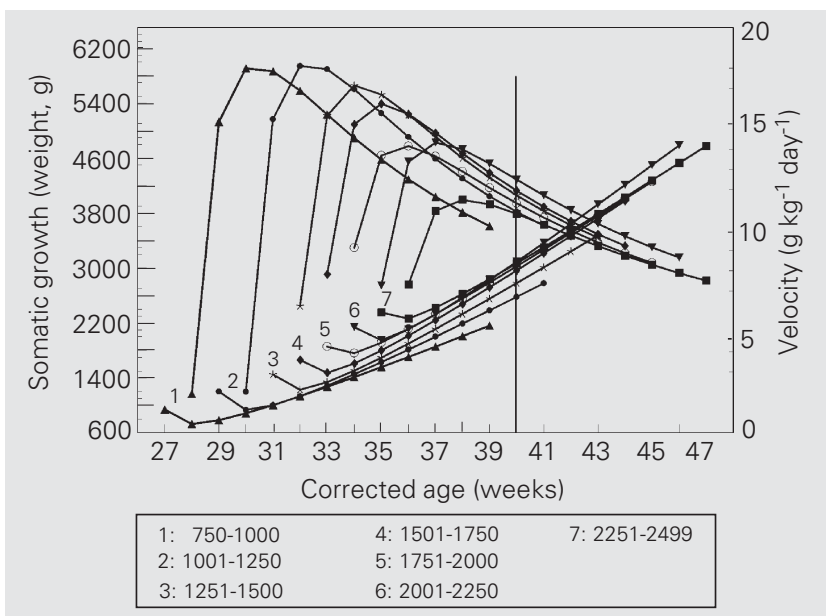

Figure 6. Growth dynamics of adequate-for-gestational-age preterm newborns: somatic growth and velocity with respect to corrected age. 
the present paper reported weight gain velocity curves.

Mean daily weight gain velocities (Figure 3) were proportional to birth weight, that is, the larger the infants, the greater the mean weight gain velocities ( $g /$ day), and these infants gained practically twice the weight gained by smaller infants in g/day. When clinical progression is efficient, there is a marked speeding up from the 1 st to the 2 nd week of life and, later on, a gradual increase up to week 7, after which weight gain becomes stable. It is important to carefully interpret these velocity curves in order not to have a false impression of little weight gain by smaller infants when compared with larger ones.

The mean weight gain velocities in $\mathrm{g} \mathrm{kg}^{-1}$ day $^{-1}$ (Figure 4) were inversely proportional to birth weight, and greater in lower birth weight babies. Speeding up of this rate was observed within the first four weeks of life, with a maximum peak on the 3 rd week. Therefore, this is the period of greater weight gain. It is interesting to note that this type of growth dynamics, i.e., growth recovery, might not be perceived when the somatic growth curve is used to monitor weight gain. However, this is the critical growth period, when the clinician should be aware of the nutritional management of preterm infants.

When comparing somatic growth (Figure 2) and its respective relative velocity (Figure 4), we observed that the group of smaller children at birth (curve 1), with a mean weight loss of $13.3 \%$, presented a recovery dynamics with a higher relative velocity peak, gaining $18 \mathrm{~g} \mathrm{~kg}^{-1}$ day $^{-1}$ (Figure 4). It is clear that the highest birth weight group (curve 7), which was also the group of neonates that lost less weight (5.9\%), had the lowest relative weight gain peak (11.5 $\mathrm{g} \mathrm{kg}^{-1}$ day $\left.^{-1}\right)$. Certainly, due to their birth weight, gestational age and clinical progression, their growth dynamics was closer to that of term infants (20). Yet, on the 12th week, there was a converging movement of all curves, with weight gain ranging from $10.2 \mathrm{~g} \mathrm{~kg}^{-1}$
Table 1. Distribution of adequate-for-gestational-age preterm newborns by weight category and gestational age at birth.

\begin{tabular}{|c|c|c|c|c|c|c|}
\hline & \multicolumn{4}{|c|}{ Birth weight (g) } & \multicolumn{2}{|c|}{$\begin{array}{l}\text { Gestational age } \\
\text { (weeks) }\end{array}$} \\
\hline & $\mathrm{N}$ & Minimum & Maximum & Mean \pm SD & Range & Mean \pm SD \\
\hline \multicolumn{7}{|l|}{ Curve 1} \\
\hline $750-1000$ & 9 & 770 & 1000 & $886.7 \pm 79.8$ & $25.4-29.6$ & $27.0 \pm 1.3$ \\
\hline \multicolumn{7}{|l|}{ Curve 2} \\
\hline $1001-1250$ & 15 & 1015 & 1235 & $1139.0 \pm 83.4$ & $25.1-31.6$ & $28.7 \pm 1.7$ \\
\hline \multicolumn{7}{|l|}{ Curve 3} \\
\hline $1251-1500$ & 40 & 1260 & 1500 & $1393.1 \pm 80.5$ & 28.6-33.7 & $31.5 \pm 1.3$ \\
\hline \multicolumn{7}{|l|}{ Curve 4} \\
\hline $1501-1750$ & 54 & 1510 & 1750 & $1634.9 \pm 70.1$ & $29.4-35.9$ & $32.5 \pm 1.5$ \\
\hline \multicolumn{7}{|l|}{ Curve 5} \\
\hline $1751-2000$ & 47 & 1755 & 2000 & $1876.5 \pm 72.8$ & $31.0-36.0$ & $33.4 \pm 1.3$ \\
\hline \multicolumn{7}{|l|}{ Curve 6} \\
\hline $2001-2250$ & 53 & 2005 & 2250 & $2118.2 \pm 71.6$ & $31.1-36.7$ & $34.4 \pm 1.4$ \\
\hline \multicolumn{7}{|l|}{ Curve 7} \\
\hline $2251-2499$ & 42 & 2260 & 2490 & $2372.5 \pm 69.8$ & $33.0-36.9$ & $35.4 \pm 0.9$ \\
\hline
\end{tabular}

day $^{-1}$ to $7.5 \mathrm{~g} \mathrm{~kg}^{-1} \mathrm{day}^{-1}$ in the lower or higher weight categories, respectively, and low birth weight infants tended to get closer to and achieve the weight of larger infants, as also reported in the literature (20-22).

For the younger gestational age groups (lower birth weight) the first weeks of postnatal life seem to be the period of expression of their own growth recovery dynamics. The catch-up growth in this study was demonstrated by the characteristics of relative weight gain velocity $\left(\mathrm{g} \mathrm{kg}^{-1} \mathrm{day}^{-1}\right)$. Some studies (20-22) have demonstrated the occurrence of this catch-up growth up to the first months after the predicted date of delivery, i.e., 40 weeks of corrected age.

It is important to observe that weight category stratification is compatible with the objective of demonstrating growth dynamics among preterm infants with birth weight ranging from 750 to $2499 \mathrm{~g}$. Nonetheless, the groups thus composed could present graphically distinct results, such as velocity curve 6 higher than curve 7 , curve 4 higher than curve 5, and curve 7 overlapping curve 5 (Figure 3) due to individual and clinical progression characteristics. Similar findings 
were also observed for velocity curves in $\mathrm{g}$ $\mathrm{kg}^{-1}$ day $^{-1}$ (Figure 4).

When postnatal progression of preterm infants is studied, several variables limit comparison of different groups of children, among them variables related not only to methodological issues, but also to the historical, cultural and social context of the children studied. However, we still tried to compare the results of the present study with those of

Table 2. Weight gain dynamics of preterm newborns.

\begin{tabular}{|c|c|c|c|c|c|}
\hline Authors & $\begin{array}{l}\text { Mean birth } \\
\text { weight (g) }\end{array}$ & $\begin{array}{c}\text { Maximum weight } \\
\text { loss (\%) }\end{array}$ & $\begin{array}{l}\text { Age at birth weight } \\
\text { recovery (days) }\end{array}$ & $\begin{array}{l}\text { Weight gain } \\
\text { (g/day) }\end{array}$ & $\begin{array}{l}\text { Weight gain } \\
\left(\mathrm{g} \mathrm{kg}^{-1} \text { day }^{-1}\right)\end{array}$ \\
\hline \multicolumn{6}{|l|}{$750-1000 \mathrm{~g}$} \\
\hline Dancis et al. (1948) (4) & 1000 & 8.0 & 17.0 & - & - \\
\hline Cooke et al. (1993) (7) & 883 & 12.0 & 12.0 & 21.0 & 14.0 \\
\hline Wright et al. (1993) (8) & 886 & 10.2 & 15.0 & 19.9 & 15.6 \\
\hline Uliani et al. (1996) (11) & 922 & 14.5 & 19.0 & 11.3 & 14.2 \\
\hline Present study & 886 & 13.3 & 21.0 & 15.9 & 18.0 \\
\hline Ehrenkranz et al. (1999) (12) & - & - & 15.7 & 19.9 & 14.4 \\
\hline \multicolumn{6}{|l|}{$1001-1250 \mathrm{~g}$} \\
\hline Dancis et al. (1948) (4) & 1250 & 8.0 & 15.0 & - & - \\
\hline Cooke et al. (1993) (7) & 1142 & 8.0 & 13.0 & 25.0 & 17.0 \\
\hline Wright et al. (1993) (8) & 1135 & 9.5 & 16.0 & 20.0 & 15.7 \\
\hline Blond et al. (1994) (10) & 1235 & 12.1 & 19.0 & 21.7 & - \\
\hline Uliani et al. (1996) (11) & 1093 & 14.5 & 20.0 & 13.7 & 14.8 \\
\hline Present study & 1139 & 12.8 & 24.0 & 20.5 & 18.1 \\
\hline Ehrenkranz et al. (1999) (12) & - & - & 13.0 & 23.8 & 15.6 \\
\hline \multicolumn{6}{|l|}{$1251-1500 \mathrm{~g}$} \\
\hline Dancis et al. (1948) (4) & 1500 & 6.6 & 14.0 & - & - \\
\hline Cooke et al. (1993) (7) & 1353 & 8.0 & 12.0 & 25.0 & 16.0 \\
\hline Wright et al. (1993) (8) & 1396 & 8.2 & 12.0 & 19.7 & 14.9 \\
\hline Blond et al. (1994) & 1514 & 7.2 & 13.0 & 21.8 & - \\
\hline Uliani et al. (1996) (11) & 1369 & 9.3 & 13.0 & 19.1 & 15.3 \\
\hline Present study & 1393 & 8.1 & 18.0 & 25.8 & 17.1 \\
\hline Ehrenkranz et al. (1999) (12) & ) - & - & 11.7 & 27.1 & 16.2 \\
\hline \multicolumn{6}{|l|}{$1501-1750 \mathrm{~g}$} \\
\hline Dancis et al. (1948) (4) & 1500 & 5.0 & 11 & - & - \\
\hline Blond et al. (1994) ${ }^{b}(10)$ & 1760 & 5.2 & 12 & 23.5 & - \\
\hline Present study & 1634 & 8.3 & 18 & 29.2 & 16.2 \\
\hline \multicolumn{6}{|l|}{$1751-2000 \mathrm{~g}$} \\
\hline Dancis et al. (1948) (4) & 1750 & 5.0 & 11 & - & - \\
\hline Blond et al. (1994)c (10) & 2012 & 6.5 & 13 & 27.3 & - \\
\hline Present study & 1876 & 7.8 & 18 & 29.9 & 14.1 \\
\hline \multicolumn{6}{|l|}{$2001-2250 \mathrm{~g}$} \\
\hline Dancis et al. (1948) (4) & 2250 & 5.3 & 10 & - & - \\
\hline Blond et al. (1994)d (10) & 2251 & 5.4 & 13 & 27.2 & - \\
\hline Present study & 2118 & 7.0 & 17 & 33.3 & 14.3 \\
\hline \multicolumn{6}{|l|}{$2251-2499 \mathrm{~g}$} \\
\hline Dancis et al. (1948) (4) & 2500 & 4.8 & 8 & - & - \\
\hline Blond et al. (1994)e (10) & 2480 & 6.6 & 16 & 16.5 & - \\
\hline Present study & 2372 & 5.9 & 17 & 30.1 & 11.5 \\
\hline
\end{tabular}

Weight range: ${ }^{\mathrm{a}} 1375-1625 \mathrm{~g}$; ${ }^{\mathrm{b}} 1625-1875 \mathrm{~g} ;{ }^{\mathrm{c}} 1875-2125 \mathrm{~g}$; ${ }^{\mathrm{d}} 2125-2375 \mathrm{~g}$; ${ }^{2} 2375-2625 \mathrm{~g}$. The number after the year of each citation identifies its position in the reference list. The present study was carried out from January to December 1996. 
other published studies, as demonstrated in Table 2.

In our study, infants with a birth weight range of 750-1000 g, 1001-1250 $\mathrm{g}$ and 1251$1500 \mathrm{~g}$ (although the samples for the first two categories were quite small) presented a mean birth weight similar to that of other studies. However, despite the fact that their weight loss percentage was similar to that of other studies, the subjects took longer to recover their birth weight. The mean caloric intake of these infants was low compared to the current recommendations of energy supply $(23,24)$, and this reduction might be related to later introduction of enteral nutrition which was slowly and gradually increased, and to a possible clinical instability of the infants, making their nutritional management difficult.

The infants with birth weight within the 1501-1750 $\mathrm{g}$ and 1751-2000 $\mathrm{g}$ ranges presented mean birth weights close to those of other studies, and these newborns also took longer to recover their birth weight, and regained weight at the hospital. However, their weight loss rate was similar to that of other reports. Although an enteral diet was introduced earlier, the infants achieved an adequate energy supply only as of the 2 nd week of life, and this fact might be associated with a more gradual increase in diet or clinical instability of infants during the first two weeks of life.

For infants with birth weight between 2001-2250 g and 2251-2499 g the weight loss rate was similar to that reported in other studies, but the mean time to achieve birth weight was longer than in other studies. An enteral diet was introduced early, with an appropriate energy supply as of the first week. It is important to highlight that for both weight categories, by the 14th day of life $50 \%$ of the infants were followed at outpatient clinics, and consequently their growth was also determined by other variables, such as socioeconomic factors. Furthermore, the infants who were kept hospitalized, and who were possibly ill, presented a lower growth rate.

We conclude that relative velocity better describes the weight dynamics of preterm infants, mainly of those with lower birth weight. The present study provides information on relative weight gain velocity which, if expressed as $\mathrm{g} \mathrm{kg}^{-1}$ day $^{-1}$, was inversely proportional to birth weight, demonstrating that lower birth weight infants gained more weight, and the velocity peak in all birth weight categories occurred during the $3 \mathrm{rd}$ week of life.

The growth curves presented here should not be considered to be optimal. The results obtained apply to the population studied; however, these curves could be useful to better understand the postnatal growth of preterm newborns, to identify factors that interfere with growth (mainly the attention that should be paid to the nutritional management of these newborns), and to contribute to future studies.

\section{References}

1. Arias E \& Smith BL (2003). Deaths: Preliminary Data for 2001. National Vital Statistics Report. National Center for Health Statistics, Hyattsville, MD, USA, 51 (5).

2. Ministério da Saúde (2003). http://www.datasus.gov.br. Accessed March 25, 2003.

3. Kipikasa J \& Bolognese RJ (1997). Obstetric management of prematurity. In: Fanaroff PA \& Martin RJ (Editors), Neonatal; Perinatal Medicine Diseases of the Fetus and Infant. 6th edn. Mosby, St. Louis, MO, USA, 264-284.

4. Dancis J, O'Connell JR \& Holt LE (1948). A grid for recording the weight of premature infants. Journal of Pediatrics, 33: 570-572.

5. Brosius KK, Ritter DA \& Kenny JD (1984). Postnatal growth curve of the infant with extremely low birth weight who was fed enterally. Pediatrics, 74: 778-782.

6. Fenton TR, McMillan DD \& Sauve RS (1990). Nutrition and growth analysis of very low birth weight infants. Pediatrics, 86: 378-383.

7. Cooke RJ, Ford A, Werkman, S, Conner C \& Watson D (1993). Postnatal growth in infants born between 700 and 1,500 g. Journal of Pediatric Gastroenterology and Nutrition, 16: 130-135.

8. Wright K, Dawson JP, Fallis D, Vogt E \& Lorch V (1993). New 
postnatal growth grids for very low weight infants. Pediatrics, 91: 922-926.

9. Itabashi K, Takeuchi T, Hayashi T, Okuyama K, Kuriya N \& Otani Y (1994). Postnatal reference growth curves for very low birth weight infants. Early Human Development, 37: 151-160.

10. Blond MH, Gold F, Kadiry LA, Rondeau C, Marchand S \& Guérois M (1994). Croissance pondérale post natale du prématuré: on peut continuer à utilisier les courbes de référence de Dancis (1948). Archives de Pédiatrie, 1: 1079-1084.

11. Uliani ACCA, Carvalho R \& Barros Filho AA (1996). Evolução ponderal de recém-nascidos de muito baixo peso. Jornal de Pediatria, 72: 388-393.

12. Ehrenkranz RA, Younes N, Lemons JA et al. (1999). Longitudinal growth of hospitalized very low birth weight infants. Pediatrics, 104 : 280-289.

13. Greco L, Capasso A, De Fusco C \& Paludetto R (1990). Pulsatile weigth increases in very low birthweight babies appropriate for gestational age. Archives of Disease in Childhood, 65: 373-376.

14. Ozkan H, Uguz A \& Haberal S (1997). Postnatal weight velocity patterns in very low birthweight infants. Indian Journal of Pediatrics, 64: 383-388.

15. Pauls J, Bauer K \& Versmold H (1998). Postnatal body weight curves for infants below 1,000 g birth weight receiving early enteral and parenteral nutrition. European Journal of Pediatrics, 157: 416-421.

16. Lubchenco LO, Hansman C, Dressler M \& Boyd E (1963). Intrauterine growth as estimated from liveborn birth-weight data at 24 to 42 weeks of gestation. Pediatrics, 32: 793-800.

17. Ballard JL, Khoury JC, Wedig K, Wang L, Eilers-Walsman BL \& Lipp $R$ (1991). New Ballard score, expanded to include extremely premature infants. Journal of Pediatrics, 119: 417-423.

18. Hauspie RC (1989). Mathematical models for the study of individual growth patterns. Revue d'Epidemiologie et de Santé Publique, 37: 461-476.

19. Draper NR \& Smith H (1981). Applied Regression Analysis. 2nd edn Wiley, New York.

20. Brandt I (1986). Growth dynamics of low-birth-weight infants with emphasis on the perinatal period. In: Falkner F \& Tanner JM (Editors), Humam Growth. 2nd edn. Plenum Press, New York, 415-475.

21. Altigani M, Murphy JF, Newcombe RG \& Gray OP (1989). Catch up growth in preterm infants. Acta Paediatrica Scandinavica. Supplement, 357: 3-19.

22. Xavier CC, Abdallah VOS, Silva BR, Mucillo G, Jorge SM \& Barbier MA (1995). Crescimento de recém-nascidos pré-termo. Jornal de Pediatria, 71: 22-27.

23. American Academy of Pediatrics Committee on Nutrition (1985). Nutritional needs of low-birth-weight infants. Pediatrics, 75: 976986.

24. European Society of Paediatric Gastroenterology and Nutrition, Committee on Nutrition of the Preterm Infant (1987). Nutrition and feeding of preterm infants. Acta Paediatrica Scandinavica. Supplement, 336: 1-14. 